\title{
Proliferative activity of gonocytes, Sertoli cells and interstitial cells during testicular development in mice
}

\author{
R. P. F. A. Vergouwen ${ }^{1}$, S. G. P. M. Jacobs ${ }^{1}$, R. Huiskamp ${ }^{2}$, \\ J. A. G. Davids ${ }^{3}$ and D. G. de Rooij ${ }^{1}$ \\ ${ }^{1}$ Department of Cell Biology, State University, Medical School, Utrecht, Netherlands; \\ ${ }^{2}$ Radiobiology and Radioecology, Netherlands Energy Research Foundation ECN, Petten, and \\ ${ }^{3}$ Lonbar Petrilaan 28, 2051 EJ Overveen, Netherlands
}

\begin{abstract}
Summary. Developing mouse testis was studied from Day 14 post coitum (p.c.) until Day 35 post partum (p.p.) by $\left[{ }^{3} \mathrm{H}\right]$ thymidine autoradiography.

The gonocytes proliferated actively at Day 14 p.c., the $\left[{ }^{3} \mathrm{H}\right]$ thymidine labelling index (L.I.) being $7.5 \%$, and were quiescent from Day 16 p.c. up to the first day of life, when spermatogenesis started. The L.I. increased to $20 \%$ at Day 2 p.p. The L.I. for the Sertoli cells was $\sim 20 \%$ before birth. After birth the proliferative activity decreased. After Day 11 p.p., the Sertoli cells showed their typical adult appearance. After Day 17 p.p. no labelled Sertoli cells were observed.

The Leydig cells featured a very low proliferative activity up to Day 21 p.p. (L.I. of maximal $1.9 \%$ ). At Day 29 p.p. there was a peak of $7.4 \%$ in L.I., followed by a sharp decrease to $0.35 \%$ at Day 35 p.p. The L.I. of mesenchymal cells decreased from $11.4 \%$ at Day 14 p.c. to $11 \%$ at Day 14 p.p. and remained more or less constant thereafter. The proliferative activity of myoid, endothelial and perivascular cells followed a similar course to that of mesenchymal cells, their L.I.s being high before birth $(16,12.5$ and $19 \%$, respectively, decreasing until Day 14 p.p. $(0 \cdot 6,2 \cdot 0$ and $1 \cdot 2 \%$, respectively) and thereafter being more or less constant. There was an increase in the relative number of Leydig cells from $\sim 4 \%$ of the total interstitial cell number at Day 14 p.p. to $29.5 \%$ at Day 35 p.p. At the same time, the relative number of mesenchymal cells decreased from 55 to $13 \%$. The diameter of the seminiferous tubules showed a peak of $92 \mu \mathrm{m}$ at Day 16 p.c., decreased to $44 \mu \mathrm{m}$ at Day 1 p.p. and increased again to $204 \mu \mathrm{m}$ at Day 33 p.p.

These results show that, except for the Leydig cells, the proliferative activity of testicular cell types is highest during the pre- and early postnatal period. The major outgrowth of the Leydig cell population occurs around the fourth week after birth. The results are in accordance with the hypothesis that the mesenchymal cells are the progenitors of Leydig cells.
\end{abstract}

Keywords: prepubertal; gonocytes; Sertoli cells; interstitial cells; proliferation; mouse

\section{Introduction}

In the testis a number of cell lineages are present, the most important being the germ cells, Sertoli cells and Leydig cells. During development each of these cell lineages follows its own path of proliferation and differentiation. Most of the data on this subject have been obtained in rats. In mice, except for the germ cells, little is known about the proliferation and differentiation of the various cell lineages in the developing testis. The gonocytes, which are the precursors of the germ cell lineage, proliferate until Days 14-16 post coitum (p.c.), depending on the strain of mice (Sapsford, 1962; Byskov, 1978; Kluin \& de Rooij, 1981), and then are arrested in the $\mathrm{G}_{1}$ phase of 
the cell cycle. After birth the gonocytes resume their mitotic activity and give rise to A spermatogonia (Sapsford, 1962; Kluin \& de Rooij, 1981). Kluin et al. (1984) studied Sertoli cell proliferation between 6 and 14 days post partum (p.p.) in mice and found that it almost stopped at 12 days p.p.

Studies concerning the interstitial tissue in mouse testis have mainly concentrated on the Leydig cells (Baillie, 1961; Hitzeman, 1962; Russo \& de Rosas, 1971). Decreasing numbers of mitotic figures of Leydig cells were found by Hitzeman (1962), between birth and Day 15 p.p. At 20 days p.p. a small peak in the mitotic activity was found and, after the sixth week, Leydig cell division ceased.

In the present investigation, we studied the proliferation and differentiation of the gonocytes, Sertoli cells, and the different types of interstitial cells in developing mouse testis from 14 days p.c. up to Day 35 after birth.

\section{Materials and Methods}

Animals. Inbred mice (strain CBA/P) were obtained from the Netherlands Energy Research Foundation (ECN), Petten, Netherlands. Mice were mated at random by placing one male with 4 females overnight, for $12 \mathrm{~h}$. The next day was considered to be the first day p.c. Pregnant females were killed by decapitation and the gonads were removed from their embryos at Days 14, 16, 18 and 20 p.c. To determine the time of birth, pregnant mice were inspected twice a day. Animals were killed at Days 1, 2, 3, 4, 9, 11, 14, 17,21, 24, 29, 33 and 35 p.p. The day of birth was taken as Day 1. At each age, the testes of 4 animals were studied.

Autoradiography. Pregnant mice or, after parturition, their male offspring received a single injection of $\left[{ }^{3} \mathrm{H}\right]$ thymidine $(5 \mu \mathrm{Ci} / \mathrm{g}$ body weight; sp. act. $49 \mathrm{Ci} / \mathrm{mmol}$ : Amersham, Buckinghamshire, UK) intraperitoneally, $1 \mathrm{~h}$ before sacrifice. The testes were fixed in Zenker-formol and embedded in Technovit 7100 (Kulzer \& Co. GmbH, Wehrheim, Germany). Sections of $5 \mu \mathrm{m}$ were stained with the periodic acid-Schiff (PAS) technique and dipped in Kodak NTB-2 nuclear emulsion (Eastman Kodak, Rochester, NY, USA). The autoradiographs were developed after 2-5 weeks of exposure at $4^{\circ} \mathrm{C}$, when labelling was evident. Counter staining was performed with haematoxylin (Gill's No-3; Polysciences, Inc., Warrington). Cells were considered labelled when at least 5 silver grains were present above the nucleus. The background was $<10$ grains $/ 10^{6} \mu \mathrm{m}^{2}$.

Histology and measurement of labelling index. Gonocytes were recognized by their large round nuclei and clearly identifiable cellular surroundings. In fetal and neonatal animals, Sertoli cells were recognized by their irregularly shaped nuclei and hardly detectable cellular surroundings. In older animals, Sertoli cells were recognized by their typical tripartite nucleolus.

Leydig, myoid, mesenchymal, endothelial and lymphatic endothelial cells, were distinguished according to the criteria described by Hardy et al. (1989) for rats. Vascular muscle cells were recognized by their large fusiform nuclei surrounding the vessels in a regular, circular pattern.

All cells that were in close contact with either the endothelial cells or the vascular muscle cells, were scored as perivascular cells. Macrophages as well as Leydig cells have abundant cytoplasm and round nuclei. Macrophages were distinguished from the Leydig cells by their purple-staining cytoplasm, often showing vacuoles which varied in number and size, and by their nuclei, which stained more darkly than those of the Leydig cells.

A total of 500 cells was counted for each of the cell types for each animal, except for the macrophages and vascular muscle cells. The latter cell types, which were rare in the younger animals, were scored until the counting for the other cell types was completed. The labelling index was calculated from the number of labelled cells, divided by the total number of cells scored, multiplied by $100 \%$.

Measurement of the relative number of interstitial cells was by counting the number of each different interstitial cell type per 500 Sertoli cells at each age. The Sertoli cells were used as reference within each age-group. The relative number was expressed as a percentage of the total number of interstitial cells.

Measurement of average tubular diameters. The average diameter of the seminiferous tubules of each animal was determined by measuring the diameter of 25 tubular cross-sections by means of image analysis using the TIM imageprocessing program, version 3.20 (Difa Measuring systems, Breda, Netherlands) and a CCD camera HTH MO (High Technology Holland, Eindhoven, Netherlands).

Statistics. Statistical analysis was performed with the aid of SPSS/PC + version 3.1. The data were analysed by ANOVAS, and significant differences between groups were identified by the $b$ Tukey test. Differences were considered to be significant if $P<0.05$.

\section{Gonocytes}

\section{Results}

At Day 14 p.c. the Sertoli cells and gonocytes were uniformly distributed within the sex cords. The morphology of the round nucleus of the gonocytes varied, probably depending on the phase of 
the cell cycle (Fig. 1a). Gonocytes were proliferating at Day 14 p.c. with a $\left[{ }^{3} \mathrm{H}\right]$ thymidine labelling index of $7.7 \pm 1 \cdot 1 \%$. From Day 16 p.c. until birth the gonocytes were located near the centre of the cords. At that time the morphology of the nuclei of the gonocytes was more uniform than at Day 14 p.c. and the nuclei were larger than those of the Sertoli cells. Gonocyte nuclei stained lightly with haematoxylin and showed one or more globular nucleoli (Fig. 1b). Labelled gonocytes were rare at 16 days p.c. (L.I. $0 \cdot 2 \pm 0 \cdot 1 \%$ ) and were absent at Days 18 and 20 p.c.

After birth the gonocytes became enlarged and moved towards the basal membrane of the tubules. Their morphology was no longer uniform as they resumed their mitotic activity. The L.I. was $10 \cdot 4 \pm 3 \cdot 1 \%$ at Day 1 p.p., significantly increasing to $20 \cdot 1 \pm 3.0 \%$ at Day 2 p.p. and $24 \cdot 1 \pm 4 \cdot 1 \%$ at Day 3 p.p. (Fig. 2). At Day 3 p.p. the first A spermatogonia were identified. These cells could be recognized by an oval nucleus and 1-5 nucleoli and they often showed a nuclear vacuole.

\section{Sertoli cells}

At Day 14 p.c., Sertoli cell nuclei were variable in size and shape and could readily be distinguished from those of the gonocytes (Fig. 1a). Between Days 16 and 20 p.c. the Sertoli cells were located at the periphery of the sex cords (Fig. 1b). The Sertoli cells showed a high L.I. during the fetal period, with a maximum of $22 \cdot 7 \pm 1 \cdot 3 \%$ at Day 16 p.c. During Day 20 p.c. and the first postnatal days, the Sertoli cell nuclei moved in the direction of the centre of the tubules and their shape changed into that of a droplet (Fig. 1c, d). The L.I. decreased significantly after birth. By Day 14 p.p. (L.I. $1.6 \pm 0.7 \%$ ) most Sertoli cells showed their adult morphology with the typical nucleolus (Fig. le, f). The number of Sertoli cells incorporating $\left[{ }^{3} \mathrm{H}\right]$ thymidine, continued to decrease significantly until Day 9 p.p. After Day 17 p.p. no labelled Sertoli cells were found (Fig. 2).

\section{Leydig cells}

At Day 14 p.c. the Leydig cells lay scattered throughout the interstitium, having a round nucleus with a nucleolus and abundant cytoplasm that could not be stained by the PAS technique. From Day 16 p.c., increasing numbers of PAS-positive Leydig cells were observed (Fig. 1b, c). The Leydig cells during prenatal and early postnatal life showed a low L.I., 1.3\%. At Day 20 p.c., the Leydig cells began to form clusters of up to 40 cells; they had a clearly PAS-positive-staining cytoplasm of granular morphology (Fig. 1c). After Day 4 p.p. more and more PAS-negative Leydig cells were found. Consequently, the relative number of Leydig cells that became stained by the PAS technique decreased, but they never disappeared completely. After Day 9 p.p. few PAS-positive Leydig cell clusters were present and single PAS-positive Leydig cells were scattered between PAS-negative Leydig cells.

The percentage of labelled Leydig cells after birth gradually, but significantly, increased from $0.5 \pm 0 \cdot 1 \%$ at Day 1 p.p. to a peak value of $6 \cdot 2 \pm 0 \cdot 7 \%$ at Day 29 p.p. and subsequently declined significantly to $0 \cdot 6 \pm 0 \cdot 2 \%$ on Day 35 p.p. (Fig. 2 ).

The relative number of Leydig cells decreased, but not significantly, from $10 \cdot 3 \pm 0 \cdot 3 \%$ at Day 16 p.c. to $3 \cdot 4 \pm 0.6 \%$ of the total number of interstitial cells at Day 2 p.p. From Day 3 up to Day 11 p.p. the interstitium contained between $4.4 \pm 1.9$ and $4.9 \pm 0.3 \%$ Leydig cells. After Day 11 p.p. the relative number of Leydig cells slowly increased to $8.5 \pm 1.3 \%$ at Day 17 p.p. and there was a significant increase to $29 \cdot 4 \pm 1.9 \%$ at Day 35 p.p. (Fig. 3).

\section{Mesenchymal cells}

The L.I. of the mesenchymal cells significantly decreased from $11.4 \pm 1.4 \%$ at Day 14 p.c. to $0.7 \pm 0.4 \%$ at Day 14 p.p. Hereafter, a more or less constant level of proliferative activity was maintained (Fig. 2). During the prenatal and the postnatal period up to Day 11 p.p., the interstitial 

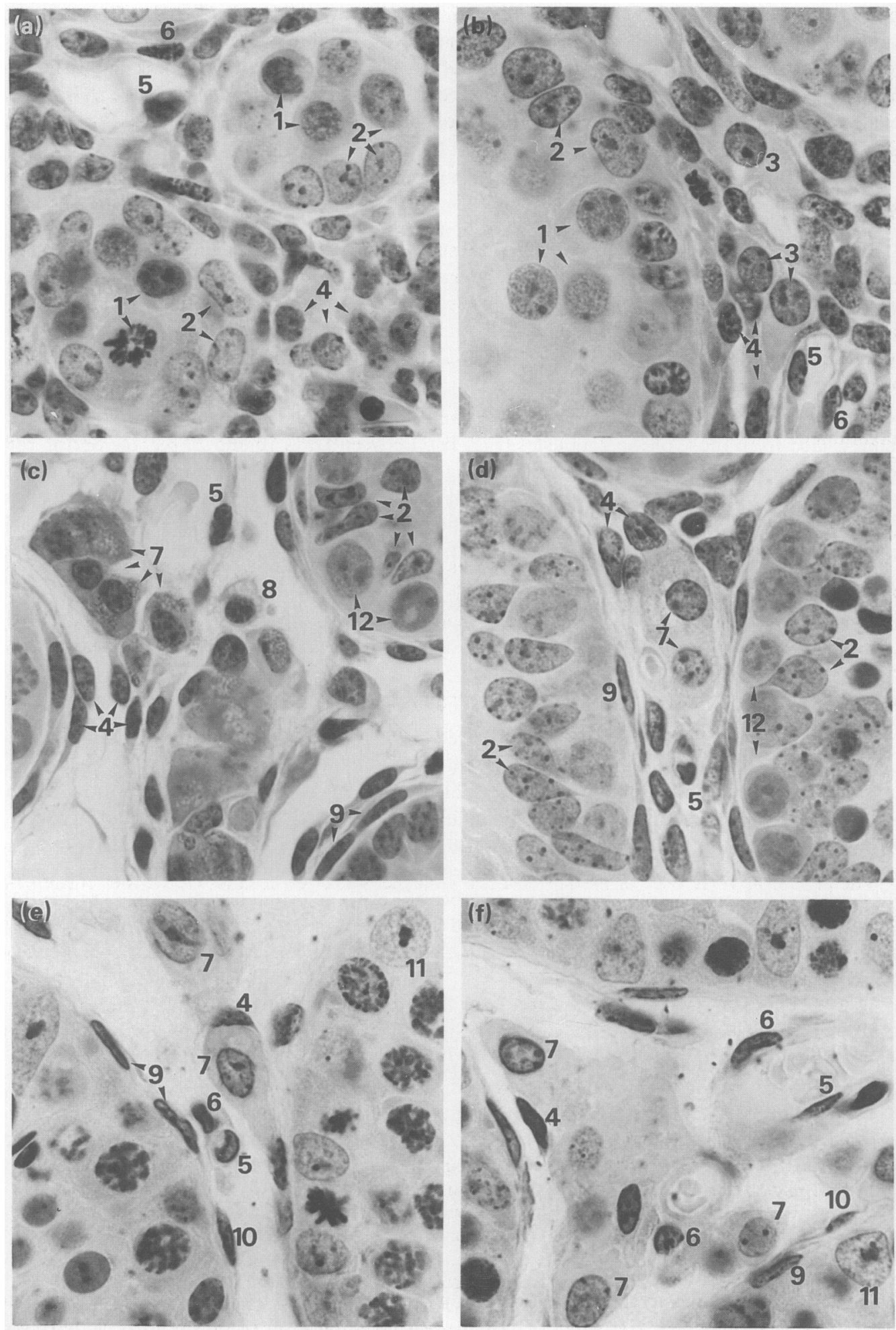
compartment of the testis consisted of $47 \cdot 6-63 \cdot 7 \%$ of mesenchymal cells (Fig. 3). However, after Day 11 p.p., with increasing age of the animals the relative number of mesenchymal cells decreased significantly, at least partly due to the fact that around Day 10 p.p. the lymphatic endothelium is formed by differentiation from the mesenchymal cells (Leeson \& Leeson, 1963). The mesenchymal cells formed $30.6 \pm 3.0 \%$ of the total number of interstitial cells at Day 14 p.p., decreasing to $13 \pm 2 \cdot 5 \%$ at Day 35 p.p. (Fig. 3 ).

\section{Myoid cells}

Before birth, the seminiferous tubules were surrounded by myoid cells that were cuboidal to fusiform and were in intimate contact with the basal lamina of the tubules (Fig. 1d, e). After birth the myoid cells became more elongated along the basal membrane of the tubules. The myoid cells had an L.I. of $\sim 16 \%$ between Days 14 and 20 p.c. Thereafter, their proliferative activity decreased significantly until Day 11 p.p. (L.I. $=2 \cdot 8 \pm 0.5 \%$ ) and thereafter L.I. was more or less constant at $\sim 1.0 \%$ (Fig. 2).

The relative number of myoid cells generally increased from $13.6 \pm 1.6 \%$ at Day 14 p.c. to a maximum of $31.7 \pm 3.4 \%$ at Day 14 p.p., followed by a significant decrease to $21 \cdot 3 \pm 1 \cdot 3 \%$ at Day 35 p.p. (Fig. 3).

\section{(Lymphatic) endothelial cells}

The $\left[{ }^{3} \mathrm{H}\right]$ thymidine L.I. of the endothelial cells showed an overall decrease from $12.8 \pm 1.8 \%$ at Day 16 p.c. to $1.9 \pm 0.4 \%$ at Day 35 p.p. (Fig. 2).

The relative numbers of endothelial cells decreased significantly from $12.8 \pm 1.9 \%$ at Day 14 p.c. to $3.4 \pm 0.4 \%$ at Day 2 p.p. Thereafter an increase was seen to $\sim 8.5 \%$ between Days 14 and 35 p.p. (Fig. 3).

Lymphatic endothelial cells could only be recognized from Day 11 p.p. onwards. The lymphatic endothelium consisted of fusiform cells that were directly adjacent to the myoid cells (Fig. 1e, f). There was a low level of proliferative activity with a mean L.I. of $\sim 0.8 \%$ (Fig. 2). From Day 11 p.p. $\sim 13 \%$ of the interstitium consisted of lymphatic endothelial cells (Fig. 3).

\section{Perivascular cells}

The proliferative activity of the perivascular cells (cells in close contact with either endothelial or vascular muscle cells; Fig. 1f) was highest at Day 16 p.c., with an L.I. of $19 \cdot 4 \pm 4.3 \%$, and

Fig. 1. Photomicrographs of testicular tissue from immature mice of different ages. PAShaematoxylin, $\times 885$. (a) Day 14 post coitum (p.c.): tubules are filled with gonocytes (1) showing nuclei of differing morphology and immature Sertoli cells (2); the interstitial space is filled with mesenchymal cells (4) and the endothelial (5) and perivascular cells (6) of small blood vessels. (b) Day 16 p.c.: gonocytes showing more uniform morphology (1) are located in the centre of the tubules, while the Sertoli cell nuclei (2) have moved to the periphery. In the interstitium some Leydig cells (3) can now be observed. (c) Day 4 post partum (p.p.): in the tubules the gonocytes have formed A spermatogonia (12) and the Sertoli cell nuclei are more or less droplet shaped (2); the tubules are surrounded by myoid cells (9) and clusters of Leydig cells with PAS-positive cytoplasm (7) are present; occasional macrophages (8) are seen. (d) Day 11 p.p.: most Leydig cells are PAS-negative now (7) and are located in the vicinity of blood vessels; Sertoli cells still appear immature (2); the relative number of mesenchymal cells (4) decreases. (e) Day 14 p.p.: in the peritubular area the lymphatic endothelial cells can clearly be recognized (10). (f) Day 33 p.p.: the testis looks fairly mature at this stage; the Sertoli cells show their adult morphology (11); relatively few mesenchymal cells are present in the interstitial compartment while the number of Leydig cells has increased. 


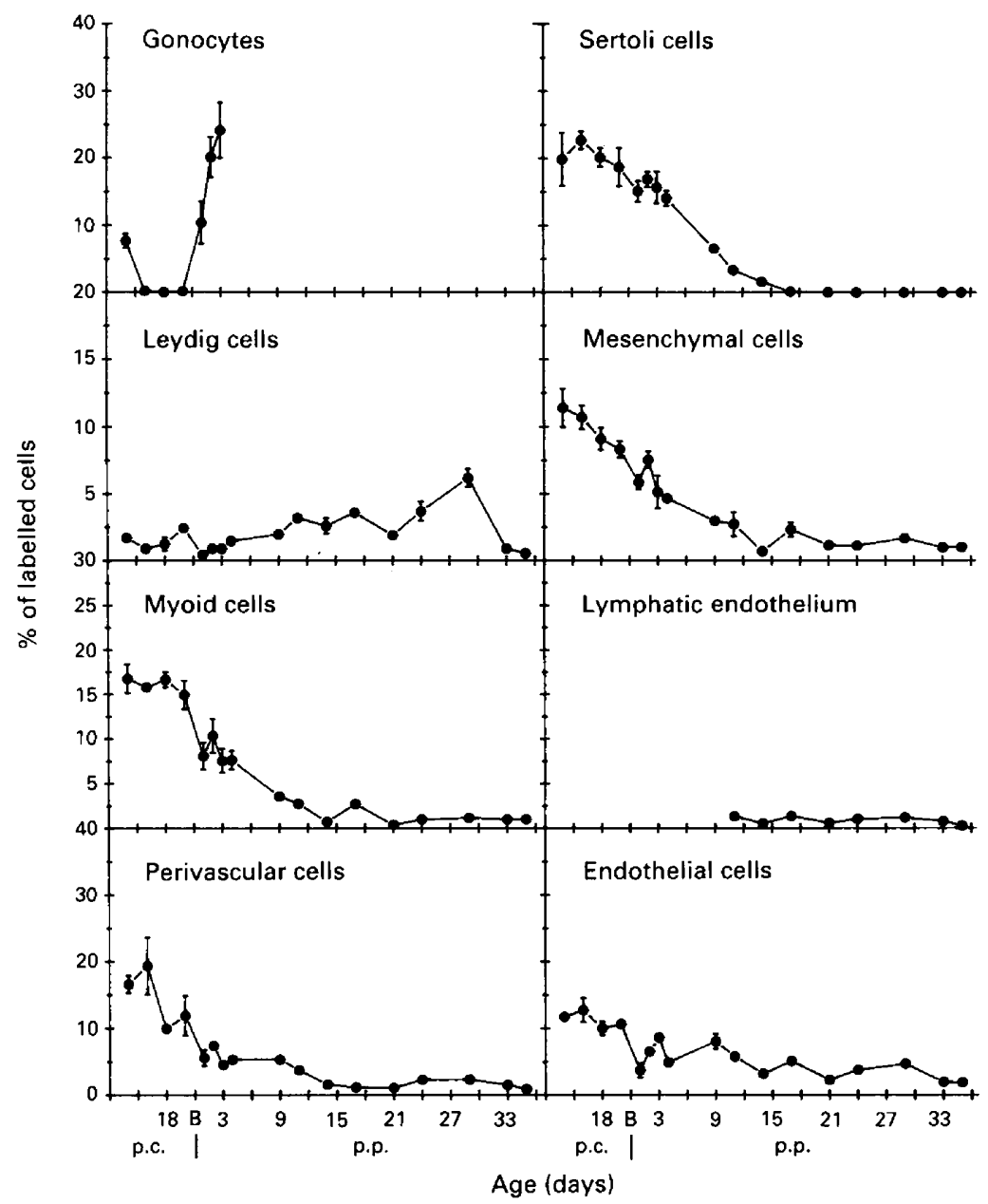

Fig. 2. $\left[{ }^{3} \mathrm{H}\right]$ thymidine labelling index of the different testicular cells, between Day 14 post coitum (p.c.) and Day 35 post partum (p.p.). Mice were killed $1 \mathrm{~h}$ after the injection of $\left[{ }^{3} \mathrm{H}\right]$ thymidine. $\mathbf{B}=$ birth. Bars indicate s.e.m.

decreased significantly to $1.6 \pm 0.6 \%$ at Day 14 p.p., after which the proliferation remained more or less constant (Fig. 2).

The relative number of perivascular cells was greatest before birth at $16 \cdot 1 \pm 5 \cdot 3 \%$ at Day 20 p.c., then decreased significantly to $\sim 5 \cdot 1 \pm 1 \cdot 0 \%$ at Day 9 p.p. and increased again, not significantly, to a mean of $\sim 8 \cdot 5 \%$ after Day 14 p.p. (Fig. 3 ).

\section{Vascular muscle cells}

The vascular muscle cells showed a period of more or less active proliferation during the first 2 weeks after birth, with a mean L.I. of $\sim 5 \%$. From Day 14 p.p. the L.I. fluctuated around $1.5 \%$.

In prenatal mice, only small blood vessels, mostly capillaries, were found. In neonatal animals, larger blood vessels appeared that consisted not only of endothelial and perivascular cells but also of vascular muscle cells. Both the number of vascular muscle cells and the L.I. were very low, and varied considerably, but not significantly, per animal. This was caused by the varying number of larger vessels, and hence vascular muscle cells, found during the counting. The relative number of 


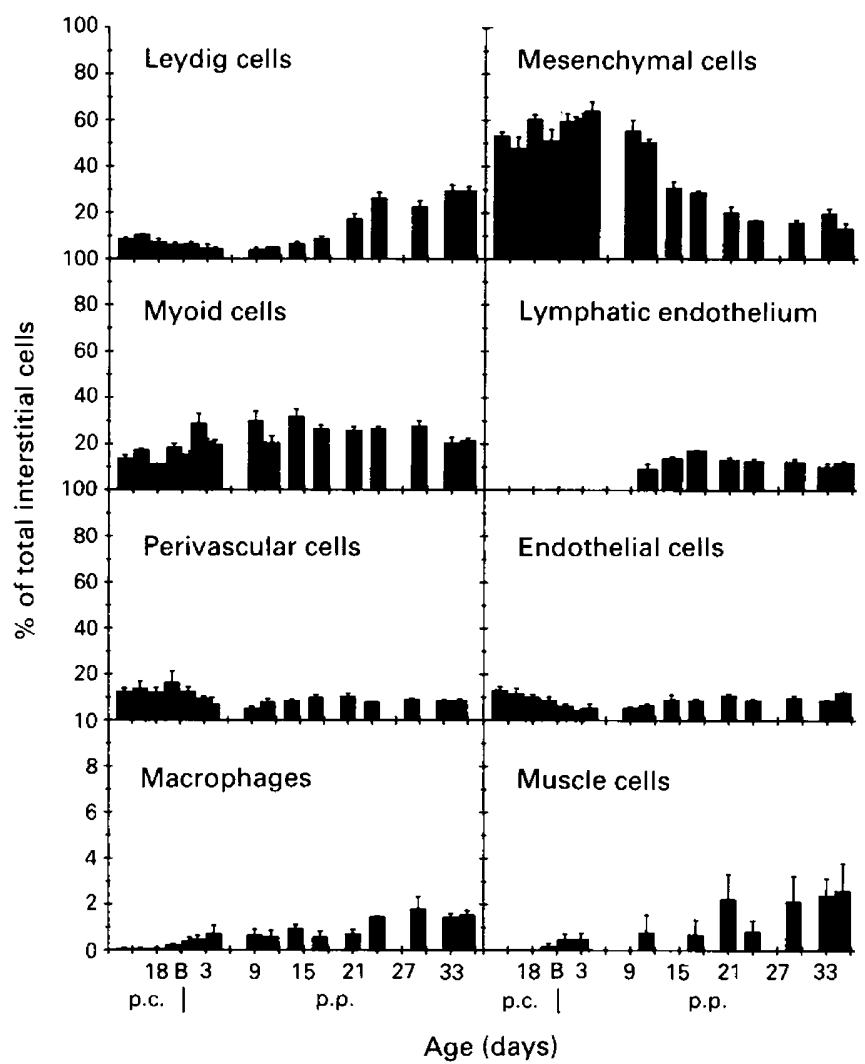

Fig. 3. Composition of mouse testicular interstitial cell compartment in percentages of the total number of interstitial cells, between Day 14 post coitum (p.c.) and Day 35 post partum (p.p.). $\mathrm{B}=$ moment of birth. Bars indicate s.e.m.

vascular muscle cells was very low and increased slowly, but not significantly, up to $2 \cdot 6 \pm 1 \cdot 2 \%$ at Day 35 p.p. (Fig. 3).

\section{Macrophages}

Up to Day 11 p.p. a mean L.I. of $10 \%$ was scored for the macrophage population. After that the rate of proliferation decreased and, from Day 17 p.p., the proliferative activity was constant with L.I. of $\sim 1 \%$. The change in proliferative activity appeared to be not significant at any time.

In fetal mice, interstitial macrophages were extremely rare, but after birth more macrophages appeared (Fig. 1C). The relative number of macrophages increased from $0.4 \pm 0.2 \%$ at birth to $1 \cdot 5 \pm 0 \cdot 2 \%$ of the total number of interstitial cells at Day 35 p.p. (Fig. 3).

\section{Tubular diameter}

At Day 16 p.c. a small peak was found in the diameter of the seminiferous tubules of $92 \pm 5 \mu \mathrm{m}$. At this time the centre of the seminiferous tubules is filled with numerous gonocytes. Thereafter, the tubular diameter decreased significantly to $44 \pm 0.5 \mu \mathrm{m}$ at Day 1 p.p., while at the same time the number of gonocytes per tubular cross-section decreased clearly from 20-30 at Day 16 p.c. to $1-4$ at Day 1 p.p. Subsequently, the tubular diameter gradually increased significantly to $204 \pm 3 \mu \mathrm{m}$ at Day 33 p.p. as the tubules expanded to accommodate the developing seminiferous epithelium (Fig. 4). 


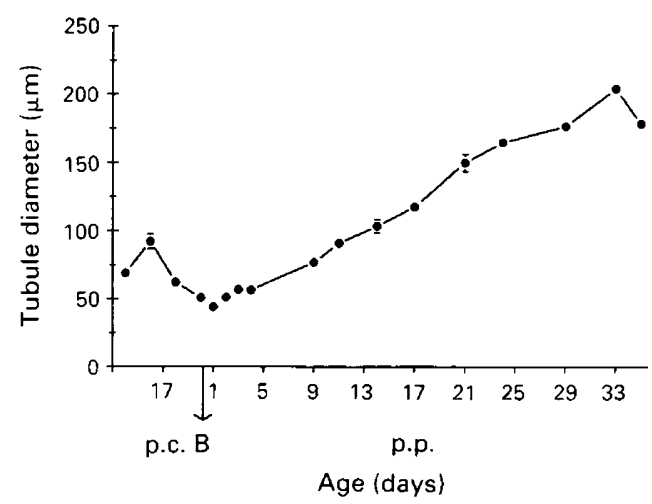

Fig. 4. Average diameter of seminiferous tubules in mice between Day 14 post coitum (p.c.) and Day 35 post partum (p.p.). B = moment of birth. Bars indicate s.e.m.

\section{Discussion}

The present results show that, in general, during testicular development the proliferative activity of the different cell types is highest before and shortly after birth. However, Leydig cells were an exception as the main outgrowth of these cells takes place after birth.

The gonocytes were actively proliferating at Day 14 p.c., but from Day 16 p.c. these cells became arrested in $G_{1}$. In an undefined mouse strain, Sapsford (1962) also found a cessation of mitotic activity, after the 16th day of fetal life; in Cpb-N mice, Kluin \& de Rooij (1984) found proliferating gonocytes on Days 13 and 14 p.c. and a subsequent $G_{1}$ arrest from Day 15 p.c. onwards. With respect to the start of spermatogenesis, in CBA/P mice, we found the first gonocytes in S-phase on the first day of life. Similar results were obtained by Kluin \& de Rooij (1984) in $\mathrm{Cpb}-\mathrm{N}$ mice in which the first gonocytes in S-phase were found $12 \mathrm{~h}$ p.p. However, Sapsford (1962) found the first mitotic figures of the gonocytes at 3 days of age. In the first week after the resumption of the mitotic activity of the gonocytes, their number diminishes and the A spermatogonia appear. In the present study, the first A spermatogonia were found at Day 3 p.p., which is in accordance with results obtained by Kluin \& de Rooij (1981) for Cpb-N mice, but 1-2 days earlier than described by Widmaier (1963) for 'albino-BLUHM' mice. Hence, there are considerable strain differences concerning the beginning and the ending of the period during which the gonocytes are arrested in the $G_{1}$ phase.

Sertoli cells proliferated most actively before birth. After birth the proliferative activity gradually decreased and came to a stop between Days 14 and 17 p.p., the latter being several days later than in Cpb-N mice (Kluin et al., 1984), in which the Sertoli cell proliferation virtually stops at Day 12 p.p. Furthermore, the L.I. in the Cpb-N mice ranged from $2 \cdot 5 \%$ at 8 days p.p. to $<0 \cdot 1 \%$ at 14 days p.p. (Kluin et al., 1984), which is lower than the L.I.s we found in the CBA/P mice, which range from 6.5\% at Day 9 p.p. to $1.6 \%$ at Day 14 p.p. Hence, provided cell cycle times do not differ much, the proliferative activity of Sertoli cells in CBA mice was higher than in $\mathrm{Cpb}-\mathrm{N}$ mice. In rats, interstrain differences in Sertoli cell proliferation have been described. In Long-Evans rats, Sertoli cell proliferation ceased at Day 15 p.p. (Steinberger \& Steinberger, 1971); but Orth (1982) found proliferating Sertoli cells in Sprague-Dawley rats up to 21 days p.p. These results indicate that in both mice and rats significant strain differences exist in the length of the period of proliferation of Sertoli cells.

The proliferative activity of the Leydig cell population was low before birth and during the first week after birth; it increased slowly during the second and third week and showed a peak at Day 29 p.p. Although we did not distinguish between fetal-type and adult-type Leydig cells, we found an 
age-correlated heterogeneity in staining intensity of the Leydig cells with the PAS technique. In fetal and early postnatal mice, the Leydig cells stained PAS positive. From Day 9 p.p., PAS negative Leydig cells were found and in older animals the ratio PAS positive:PAS negative shifted clearly in favour of PAS negative Leydig cells. In rats, Roosen-Runge \& Anderson (1959) observed the same phenomenon and considered a PAS-positive reaction of the cytoplasm to be an important characteristic of the fetal Leydig cells. If this is correct, the first adult Leydig cells appear in CBA/P mice 4-9 days p.p., earlier than observed in rats, where adult Leydig cells can be recognized for the first time at 10 days p.p. (Mendis-Handagama et al., 1987; Kerr \& Knell, 1988).

The development of new Leydig cells can take place by proliferation of these cells themselves, or by differentiation from interstitial precursor cells (Hardy et al., 1989). In adult rats, the latter occurs after the specific destruction of the existing Leydig cell population by ethane dimethyl sulphonate (Kerr et al., 1985; Molenaar et al., 1985; Molenaar et al., 1986; Morris et al., 1986; Teerds et al., 1989). It is still unclear which type of interstitial cell is the precursor cell that gives rise to the adult Leydig cell population in the prepubertal animal. Both mesenchymal cells (Mancini et al., 1963; Chemes et al., 1976) and peritubular myoid cells (De Kretser, 1967; Fawcett \& Burgos, 1960) have been proposed. Hardy et al. (1989) suggested that in prepubertal rat testis, the rapid increase in the number of mature Leydig cells is initiated by recruitment of mesenchymal precursor cells. They found a high $\left[{ }^{3} \mathrm{H}\right]$ thymidine incorporation of the mesenchymal cells $(\sim 17.5 \%)$ up to 14 days p.p., which decreased thereafter. At the same time, there was an increase in the L.I. of the Leydig cells. Furthermore, they noticed that the percentage of mesenchymal cells of the total number of interstitial cells decreased from $48 \%$ at 14 days p.p. to $\sim 10 \%$ at 35 days p.p. The percentage of Leydig cells increased during the same period from $7 \%$ to $>40 \%$ of the total number of interstitial cells. In the present study, the L.I. of the mesenchymal cells decreased from $12 \%$ at Day 14 p.c. to $\sim 2 \%$ from Day 14 p.p. onwards. In contrast, in mice the L.I. of the Leydig cells increased later, i.e. between days 21 and 29 p.p. Hence, in mice the decrease of the proliferative activity of mesenchymal cells is not directly followed by Leydig cell proliferation, as is the case in rats (Hardy $e t$ al., 1989). However, in CBA/P mice, the percentage of mesenchymal cells of the total number of interstitial cells decreased from 50 to $13 \%$ between Days 11 and 35 p.p., while the percentage of the Leydig cells increased from 5 to $29 \%$. This is similar to what happens in rats and it in accordance with differentiation of mesenchymal cells into Leydig cells after Day 11 p.p.

The percentages of the peritubular myoid cells of the total number of interstitial cells do not change significantly after Day 9 p.p. This does not support the idea that these cells differentiate into Leydig cells. Furthermore, the proliferative activity of the myoid cells is very low after Day 14 p.p. Hence, in mice there is no indication that the myoid cells are precursor cells for the adult Leydig cell population.

We were able to recognize the lymphatic endothelial cells from 10 days p.p. This corresponds with the moment of differentiation of the lymphatic endothelium from mesenchymal cells in the rat (Leeson \& Leeson, 1963).

In fetal mouse testis, only $0 \cdot 05 \%$ of the interstitial cells were macrophages. This number seemed to rise somewhat with increasing age (1.5\% at Day 35 p.p.). There are conflicting reports on the number of macrophages in the immature testis. According to Hardy et al. (1989), in fetal rats the number of macrophages is $\sim 10 \%$ of the total number of interstitial cells, decreasing to $3.8 \%$ at 14 days p.p. and increasing again to $14.2 \%$ at 56 days p.p. However, Themmen et al. (1987) were not able to detect any macrophages in isolated interstitial cells from immature rats (21-24 days old) either by morphological criteria or by the phagocytic properties normally seen in macrophages. Macrophages are numerous in the testis of the adult rat and mouse, being $\sim 20 \%$ of the total number of interstitial cells (Hume et al., 1984; Niemi et al., 1986; Themmen et al., 1987).

The average tubular diameter showed a peak at Day 16 p.c. and decreased again until Day 1 p.p. This temporary decrease can be explained by the fact that both the gonocytes and the Sertoli cells are still proliferating at Day 14 p.c. and Day 15 p.c.; but between Day 16 p.c. and Day 1 p.p. the gonocytes do not proliferate, while the length of the tubules keeps increasing because of Sertoli 
cell proliferation (Clermont \& Huckins, 1961). Consequently, the relative number of gonocytes per tubule decreases, causing the tubular diameter to decrease also. At Day 1 p.p., spermatogenesis starts and the number of germ cells present in the seminiferous tubules increases quickly, forcing the tubular diameter to increase again.

The present results provide an overview of the proliferative activity of the various cell lineages in the developing testis. The data will be used as a basis for predicting and studying the effects of cytotoxic agents and radiation on testicular development, in mice.

The authors wish to thank H. J. G. van der Kant and R. Dol for their skilful technical assistance and A. N. van Rijn for taking the photographs. This work was supported by the J. A. Cohen Institute for Radiopathology and Radioprotection, Leiden.

\section{References}

Baillie, A. (1961) Observations on the growth and histochemistry of the Leydig tissue in the postnatal prepubertal mouse testis. J. Anat. 95, 357-370.

Byskov, A.G. (1978) The meiosis inducing interaction between germ cell and rete cells in the fetal mouse gonad. Ann. Biol. Anim. Biochem. Biophys. 18, 327334.

Chemes, H.E., Rivarola, M.A. \& Bergada, C. (1976) Effect of hCG on the interstitial cells and androgen production in the immature rat testis. J. Reprod. Fert. 46, 279-282.

Clermont, Y. \& Huckins, C. (1961) Microscopic anatomy of the sex cords and seminiferous tubules in growing and adult male albino rats. Am. J. Anat. 108, 79-97.

De Kretser, D.M. (1967) The fine structure of the testicular interstitial cells in men of normal androgenic status. Z. Zellforsch. Mikrosk. Anat. 80, 594-609.

Fawcett, D.W. \& Burgos, M.H. (1960) Studies on the fine structure of the mammalian testis. II. The human interstitial tissue. Am. J. Anat. 107, 245-269.

Hardy, M.P., Zirkin, B.R. \& Ewing, L.L. (1989) Kinetic studies on the development of the adult population of Leydig cells in testes of the pubertal rat. Endocrinology 124, 762-770.

Hitzeman, S.J.W. (1962) Development of enzyme activity in the Leydig cells of the mouse testis. Anat. Rec. 143, 351-361.

Hume, D.A., Halpin, D., Charlton, H. \& Gordon, S. (1984) The mononuclear phagocyte system of the mouse defined by immunohistochemical localization of antigen F4/80: Macrophages of endocrine organs. Proc. Natl Acad. Sci. USA 81, 4174-4177.

Kerr, J.B., Donachie, K. \& Rommerts, F.F.G. (1985) Selective destruction and regeneration of rat Leydig cells in vivo. Cell Tiss. Res. 242, 145-156.

Kerr, J.B. \& Knell, C.M. (1988) The fate of fetal Leydig cells during the development of the fetal and postnatal rat testis. Development 103, 535-544.

Kluin, Ph.M. \& de Rooij, D.G. (1981) A comparison between the morphology and cell kinetics of gonocytes and adult type undifferentiated spermatogonia in the mouse. Int. J. Androl. 4, 475 493.

Kluin, Ph.M., Kramer, M.F. \& de Rooij, D.G. (1984) Proliferation of spermatogonia and Sertoli cells in maturing mice. Anat. Embryol. 169, 73-78.

Leeson, C.R. \& Leeson, T.S. (1963) The postnatal development and differentiation of the boundary tissue of the seminiferous tubule of the rat. Anat. Rec. 147, 243-249.

Mancini, R.E., Vilar, O., Lavieri, J.C., Andrada, J.A. \& Heinrich, J.J. (1963) Development of Leydig cell in the normal human testis. A cytological, cytochemical and quantitative study. Am. J. Anat. 112, 203-212.

Mendis-Handagama, S.M.L.C., Risbridger, G.P. \& de Kretser, D.M. (1987) Morphometric analysis of the components of the neonatal and the adult rat testis interstitium. Int. J. Androl. 10, 525-534.

Molenaar, R., de Rooij, D.G., Rommerts, F.F.G., Reuvers, P.J. \& van der Molen, H.J. (1985) Specific destruction of Leydig cells in mature rats after in vivo administration of ethane dimethyl sulphonate. Biol. Reprod. 33, 1213-1222.

Molenaar, R., de Rooij, D.G., Rommerts, F.F.G. \& van der Molen, H.J. (1986) Repopulation of Leydig cells in mature rats after selective destruction of the existent Leydig cell population with ethylene dimethyl sulphonate (EDS) is dependent on LH and not FSH. Endocrinology 118, 340-354.

Morris, I.D., Phillips, D.M. \& Bardin, C.W. (1986) Ethylene dimethane sulphonate destroys Leydig cells in the rat testis. Endocrinology 118, 709-719.

Niemi, M., Sharp, R.M. \& Brown, W.R. (1986) Macrophages in the interstitial tissue of the rat testis. Cell Tiss. Res. 243, 337-344.

Orth, J.M. (1982) Proliferation of Sertoli cells in fetal and postnatal rats: A quantitative autoradiographic study. Anat. Rec. 203, 485-492.

Roosen-Runge, E.C. \& Anderson, D. (1959) The development of the interstitial cells in the testis of the albino rat. Acta Anat. 37, 125-137.

Russo, J. \& de Rosas, J.C. (1971) Differentiation of the Leydig cell of the mouse testis during the fetal period-an ultrastructural study. Am. J. Anat. 130, $461-480$.

Sapsford, C.S. (1962) Changes of the cells of the sex cords and seminiferous tubules during the development of the testis of the rat and mouse. Aust. J. Zool. 10, 178-194.

Steinberger, A. \& Steinberger, E. (1971) Replication pattern of Sertoli cells in maturing rat testis in vivo and in organ culture. Biol. Reprod. 4, 84-87.

Teerds, K.J., de Rooij, D.G., Rommerts, F.F.G., van de Hurk, R. \& Wensing, C.J.G. (1989) Proliferation and differentiation of possible Leydig cell precursors after 
destruction of the existing Leydig cells with ethane dimethyl sulphonate: The role of $\mathrm{LH} /$ human chorionic gonadotrophin. J. Endocr. 122, 689-696.

Themmen, A.P.N., Molenaar, R., Visser, W.J., Jongkind, J.F., Rommerts, F.F.G. \& van der Molen, H.J. (1987) Comparison of the cellular composition and steroidogenic properties of preparations of interstitial cell isolated from immature and mature rat testis. $J$. Endocr. 112, 361-366.

Widmaier, R. (1963) Úber die postnatale Hodenentwicklung und Keimzellreifung bei der Maus. Zeitschr. Mikr. Anat. Forsch. 70, 215-241.

Received 30 November 1990 